\title{
Using social network analysis to document science festival partnerships
}

\section{Christine A. Bevc, Denise Young and Karen Peterman}

\begin{abstract}
This study applies social network analysis to explore the role that one science festival has played in building the state's STEM learning ecosystem. It examines the breadth and extent of collaboration among STEM educators and their partners, reviewing past and present partnerships across 449 events during the 2015 festival. Three case studies provide in-depth illustrations of partnerships. These findings represent an important step towards (a) mapping a STEM learning ecosystem, and (b) trying to understand how a festival affects the ecosystem itself. Together, study results demonstrate how the festival has served to stimulate and foster STEM partnerships.
\end{abstract}

Keywords

Informal learning; Participation and science governance; Public engagement with science and technology

Science festivals are one of the most rapidly growing and exciting forms of public engagement with science. They are dynamic, action-packed celebrations that are as diverse as the communities where they take place. Many festivals are inclusive of a broad range of STEM (science, technology, engineering, and mathematics) disciplines; some also integrate the arts and humanities in the service of promoting STEM.

In 2015, almost two million people attended science festivals in the United States alone [Science Festival Alliance, 2015]. The precise number of science festivals worldwide is not known, though it has been estimated to be around 265 [Wiehe, 2016]. While each science festival has unique features that reflect its region and scope, there are some common characteristics that define these multi-faceted events. Festivals are often distinguished from other science outreach activities in that they are celebratory in nature, reoccur (usually annually), only last for a defined amount of time (such as a weekend or two weeks), and generally present a coherent theme and/or brand [Bultitude, McDonald and Custead, 2011].

Festivals provide the public with new science engagement experiences, including opportunities to interact with STEM practitioners. Festival attendees have been found to report higher outcomes and ratings when they have the opportunity to interact with a scientist directly [Manning, 2013; Robertson and Peterman, 2013], and "mystery shopper" observations have confirmed a relation between the 
quality of scientists' interactions and the ratings provided to describe those experiences [Peterman and Young, 2015]. Wiehe [2014] explained the potential for longer-term outcomes of festivals as well, stating that participants are also likely to research something related to the science they interacted with during a festival and that they are likely to participate in other science-related activities in the weeks after attending a festival.

For the festivals themselves, one of the major outcomes is collaboration [Wiehe, 2014]. The organizational structures of festivals are as varied as the events themselves, but many rely on both an administrative leader as well as advisory, outreach, and programmatic committees to produce the festival. Science festivals are typically born out of community collaboration and implemented by dozens or more partners. As such, they reflect the rich, complex environment of science education often referred to as a STEM learning ecosystem. STEM learning ecosystems have been described as a collection of individual actors (such as schools, afterschool and summer programs, science centers, and museums) that are interconnected in symbiotic relationships that evolve over time [Traphagen and Traill, 2014]. When an entity organizes the ecosystem itself, serves as an anchor for the ecosystem and creates capacity and collaboration, it is considered an ecosystem driver. Brokering then occurs within the ecosystem as "acts of helping people move from one setting into another setting that might be inaccessible to them" [Penuel and Bevan, 2014, p. 11]. Science festivals typically include the full range of actors from across the STEM learning ecosystem and thus have the potential to serve as ecosystem drivers and/or brokers, connecting the diverse range of STEM learning opportunities, organizations, and learners in their local area.

In 2014, the Committee on Successful Out-of-School STEM Learning commissioned a paper documenting new approaches for measuring STEM learning ecosystems [Barron, 2014]. Maps of learning partnerships within networks were identified as one of the three evaluation approaches in need of further study. Barron specifically notes the need to assess whether we can "increase the breadth and depth of learning partnerships among STEM learning and among STEM educators" (p. 15) Similarly, the National Research Council [2015] has noted the need for evaluation that focuses on "how a given program fits within the larger learning ecosystem, documenting how it diversifies, deepens, or enhances possibilities for STEM learning in a given community" (p. 35).

This study is an important step in both (a) mapping a STEM learning ecosystem and (b) trying to understand how a festival affects the ecosystem itself. The study applies social network analysis to explore the role that the North Carolina Science Festival has played in the state's STEM learning ecosystem. Social network analysis offers the ability to capture and summarize the level and types of interactions among organizational actors in a system. Network data are unique, in comparison to other types of survey and evaluation results, in their representation of relational data, which enables the researcher to connect the actor or entity to the larger pattern of social structure [Scott, 2000; Wasserman and Faust, 1994]. In network data, the unit of analysis consists of the "collection of individuals and the linkages among them," regardless of whether the linkages occur among dyads (two actors), triads (three actors), or larger groups of individuals or entities [Wasserman and Faust, 1994, p. 5]. 
This study examines the breadth and extent of collaboration among event host organizations and their partners, reviewing the past and present partnerships among STEM outreach providers who hosted a total of 449 public events during the 2015 North Carolina Science Festival. Two groups were of interest: (a) host organizations that registered and organized festival events and (b) partners who assisted host organizations in the creation of festival events. Using a combination of descriptive and social network analysis methods, the data collected from host organizations was used to investigate collaboration. The initial analysis differentiated between the types of organizations and the assistance provided as part of festival activities. Additional analyses explored the extent to which partnerships were initiated, sustained, and extended beyond the festival. Together, these results begin to demonstrate how the festival has served to stimulate and foster STEM partnerships over the past five years.

The North Carolina Science Festival (NCSF) coordinates a two-week STEM celebration throughout the state. The NCSF offers hands-on learning experiences, demonstrations, tours, performances, talks, and online programs designed to educate, inspire, and make relevant the science of daily life. A goal of the NCSF is to engage people of all ages, backgrounds, and interests in every community of the state. To achieve this goal, the NCSF is structured to establish partnerships to create the festival schedule of activities. Host organizations develop, implement, and advertise their activities with support from a central festival staff at Morehead Planetarium and Science Center in Chapel Hill. Collaboration among host organizations is not a requirement of festival participation, though it is informally encouraged, supported, when applicable, and enabled, if festival staff are aware of collaborative interests among individual event hosts. Host organizations fall into two distinct categories: those that host public events, and organizations that provide programs for school-based audiences. As a result of these partnerships, the 2015 NCSF engaged 380,000 people in 980 events - both public and school-based — that took place in 93 of North Carolina's 100 counties.

Sample

The current study focused on 449 public events (rather than school-based events) staged by 214 event hosts and their partners. Public events were chosen because their format and implementation are determined by the host organization, rather than prescribed by the festival team. Public events were also of interest because they are open to the community and thus have the potential for greater scope in the partnerships they utilize. The lead contact for each public event was invited to complete the survey. A total of 214 event hosts received invitations to participate in both the pre- and post-event questionnaire.

Event hosts were invited to participate in either the single event or multiple event pre-event questionnaire, based on the number of events hosted. A total of 195 event hosts completed the pre-event questionnaire and 201 completed the post-event questionnaire. Combined, the final response rate was $87 \%$ matched pre-post responses, representing 184 unique event hosts and 376 events in total. 
Two types of data were collected for this study. The primary data source was an event-based, egocentric design survey [Marsden, 2005] that was used to generate the network, based on individual (i.e., ego) responses to survey questions. Survey questions identified and defined the relationships between host organizations and the partners they worked with to create and implement event(s) during the 2015 NCSF. Case study interviews were conducted with three host organizations to provide examples of the kinds of partnerships formed and sustained as part of the festival.

Social network questionnaire. Using Dillman's Tailored Design Method [Dillman, Smyth and Christian, 2014] for data collection, an electronic questionnaire was designed within an online survey platform. Data originally provided by event hosts in the festival registration database were used to populate a customized list of festival partners for each survey participant. For the pre-event questionnaire, parallel versions of the survey were created for those who hosted a single festival event and for those who hosted multiple events. Pre-event data collection occurred in February and March 2015. Personalized email reminders were sent along with general mailing reminders at several points during the collection period. In addition, individual reminder calls to event hosts were conducted beginning in early March, using a consistent call script. Post-event data were collected in May and early June 2015 using a similar methodology. A single questionnaire was used for both single and multiple event hosts. Using skip patterns and survey logic, the post-event survey identified additional partners that had joined host organizations since the completion of the pre-event survey.

Partners were identified by host organizations within the survey itself by using an expanding selection format. The question began with a fixed list of partners that were collected in the host organization's event registration form. Open-ended, name generator questions were then used to help respondents identify additional partners that were assisting with festival events. In the pre- and post-event questionnaires, the generator questions focused on those partners that provided assistance to the host organization. Additional questions collected details about the types of partners and assistance provided, as well as information regarding collaboration both in previous festivals and STEM learning activities beyond the festival. Event partners could provide assistance through a range of activities attending planning meetings, cohosting the event, coordinating and/or leading event activities, exchanging ideas and/or information, offering in-kind resources, and/or providing financial support to the benefit of the event.

Network generation. Using the collected organizational and relational data, the network of the NCSF was constructed. As noted, the network was bounded by an event-based approach, whereby inclusion was determined through a preset classification of participation in festival events and activities. To generate the event host network, a valued network edgelist containing the relations of each host organization ( $i$ ) and their alters $(j)$ - partners - was created. The types of assistance provided by partners were included as edgelist values. As part of this process, each organization was assigned a unique identifier within the edgelist coding. The identifiers, along with additional organizational-level measures, were 
catalogued in the network's complementary network attribute file. These measures included classification and coding of organization type, host/partner identity, and number of events hosted. The complete edgelist was used to generate the whole network of the NCSF, with individual sub-networks generated from the edgelist values. All networks were generated and analyzed in $\mathrm{R}$, using the statnet suite of packages [Handcock et al., 2003].

Case study interviews. Phone interviews were conducted with three host organizations to gather stories about their experience working with partners as part of the festival. Three host organizations - an informal learning institution, a university, and a middle school - were selected based on their post-event questionnaire data to represent best-case scenarios from across a range of contexts. Interviews were conducted with the lead team member(s) from each site using a protocol that was divided into two sections: institutional involvement with the festival, and festival partnerships. Two interviews were conducted by phone and one was conducted in person. Interviews lasted approximately one hour. All were audio-recorded and transcribed. The primary theme(s) from each were then used to create summaries to illustrate the network analysis results.

The social network analysis for this study, conducted in concert with the 2015 NCSF, captures, quantifies, and describes the partnerships that have been generated and maintained through festival events and activities. Survey responses were used to generate the NCSF network, which represents the combination of organizations and activities that contributed to the 2015 Festival. Figure 1 reflects the total reported festival network ${ }^{1}$ of event host organizations and their partners. The orange circles (vertices) represent host organizations and blue circles (vertices) represent partners; the gray lines indicate a partnership between the organizations. The total festival network consists of 659 partnerships that includes 184 event hosts and their 273 partners. Combined, there were 457 unique organizations. The network density - that is, the number of partnerships present with respect to the total possible partnerships - was very low at 0.0032 . Despite this low density, the network's overall connectedness (0.3397), or the ability to reach or connect with all other organizations in the network, was found to be modest, indicating that the NCSF network has the ability to connect directly to one out of three organizations. This finding is considerably more important and reflects a relatively high level of connectedness, particularly given the highly independent nature of festival events. The overall degree of centralization (0.0256) was very low, reflecting the highly decentralized and distributed nature of the festival across the state.

On average, host organizations partnered with two organizations, although some event hosts worked with upwards of 25 organizations. Some partnering organizations were also found to support multiple event hosts, with 75 (26\%) partners working with two or more host organizations (range: 2 to 5). A small number of host organizations also served as partners for other hosts in the network $(16 \%)$. These represent $6 \%$ of the partnerships in the network, reflecting a small aspect of the collaborative potential of festival events.

\footnotetext{
${ }^{1}$ In the figures below, these networks are illustrated using a graph-theoretic layout [Fruchterman and Reingold, 1991], whereby the placement of the vertices is governed by a basic spring-embedded algorithm to determine the distance between them.
} 


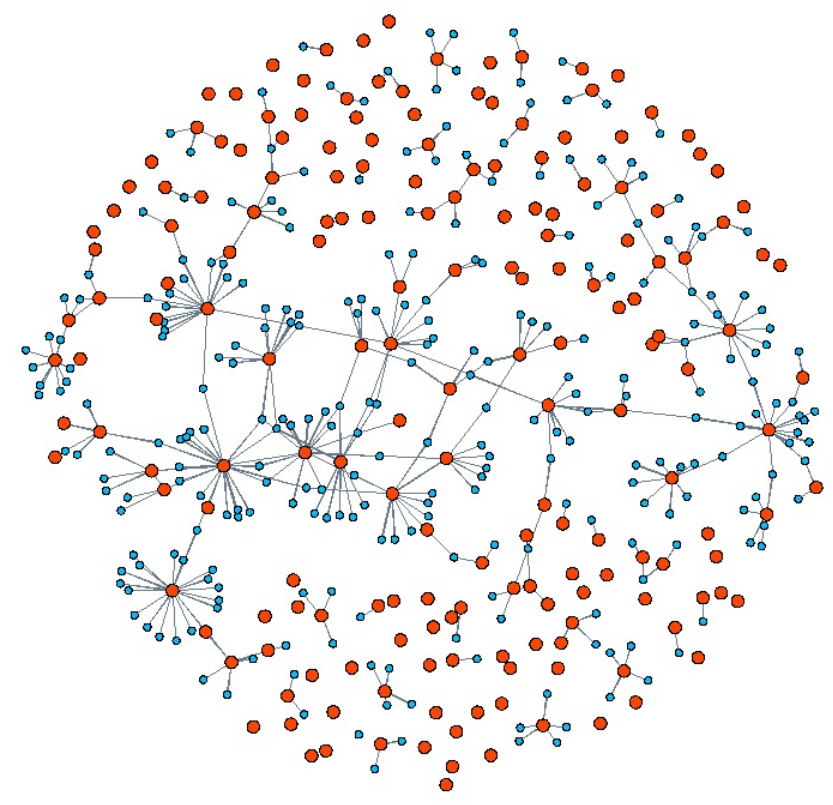

Figure 1. Social Network Graph of Festival Host Organizations and Partners.

Figure 2 compares the total percentage distribution of the different types of organizations represented by the festival's event hosts and their partners. Host organizations varied, with colleges and universities (22\%) and informal learning institutions such as museums and aquariums (18\%) being the most common. Host organizations also included nonprofits $(16 \%)$, government organizations $(14 \%)$, and K-12 schools (11\%). A small number of public and private green spaces $(7 \%)$, libraries (5\%), private businesses (5\%), and news and media outlets (1\%) also served as host organizations.

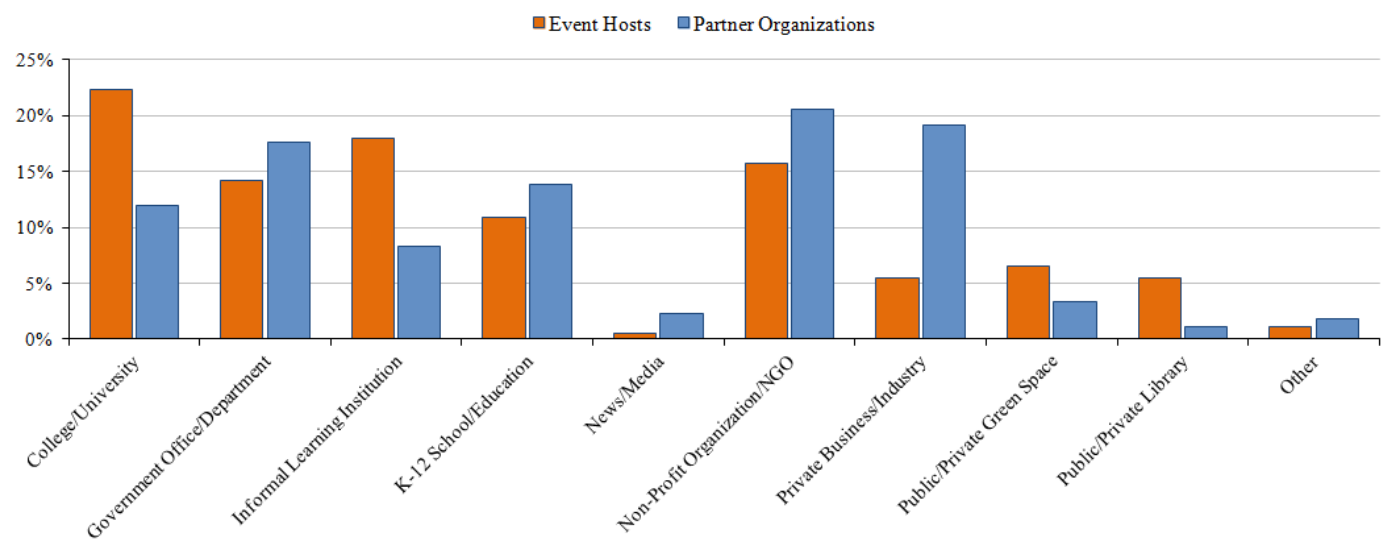

Figure 2. Types of Organizations, Comparing Event Hosts and Partners.

Like host organizations, festival partners represented a range of organization types. Nonprofit organizations (20\%), private businesses (19\%), and government organizations $(17 \%)$ were the most common. K-12 schools $(14 \%)$, colleges and universities (12\%), and informal learning institutions (8\%) also served as partners. Partnerships with public and private green spaces $(3 \%)$, news and media organizations $(2 \%)$, public and private libraries $(1 \%)$, and other organizations $(2 \%)$, including collective programs and private donors, were less common. 
The total NCSF network is composed of all partnerships and interactions between the event hosts and partner organizations. In total, these interactions reflect the range of six types of assistance measured for each reported partnerships $(n=362)$. The most common type of assistance from partners was to coordinate and/or lead event activities (64\%). Partners also exchanged ideas and/or information (40\%) and offered in-kind resources (36\%). Others were reported to have attended planning meetings (31\%), assisted by cohosting the event (19\%), and/or providing financial support $(12 \%)$. On average, partners offered two types of assistance, with a range of one to six.

Differentiating the complete network by these types of assistance across the festival network (Figure 3), we can more clearly see the ways that organizations work together to produce festival events (with network isolates removed). The coordination and leading of events remains a generally, well-connected network of partnerships, whereas the provision of financial support reflects a relatively fragmented and dyadic network of assistance between event hosts and their partners. Given the diverse nature of these different networks, whether organizations are "reachable" through the network may be more or less desirable, i.e. the provision of financial support may not be a form of assistance that is readily shared or suggested as a means of unifying the network, whereas a higher degree of connectedness, as associated with coordination, would be desirable as events are scheduled, planned, and executed across the state. In a decentralized network such as the festival, the lack of centralization in these networks is preferred and reflects the relatively independent nature of festival events.

When we look more closely at the types of organizations that provided these varying forms of assistance (Table 1), after helping to coordinate and/or lead event activities, the specific type of assistance varies by organization. For example, K-12 schools and nonprofit organizations also assisted in exchanging information and ideas, whereas government offices/departments and news/media partners offered in-kind resources. Here again, assistance provided is not mutually exclusive, providing multiple opportunities for event hosts and partner organizations to work together.

\section{History and nature of partnerships}

While festival events that relied on partnerships only represent $23 \%$ of all 2015 events, a total of 362 partnerships were developed. Almost half of these partnerships (47\%) were new collaborations established through the 2015 festival. Event hosts initiated an average of three new partnerships for their 2015 festival programs. In addition, $21 \%$ of partnerships were initiated as a direct result of past festivals. The festival provides the opportunity to continue existing partnerships year after year. Approximately half $(52 \%)$ of host organizations leverage previous partnerships to create their festival programming.

The strength of the festival network is reflected, in part, by the duration of partnerships over time. In 2015, more than three-quarters (86\%) of the existing partnerships were between organizations that had worked together in the 2014 festival. Looking further back, nearly two-thirds (64\%) of the partnerships went 


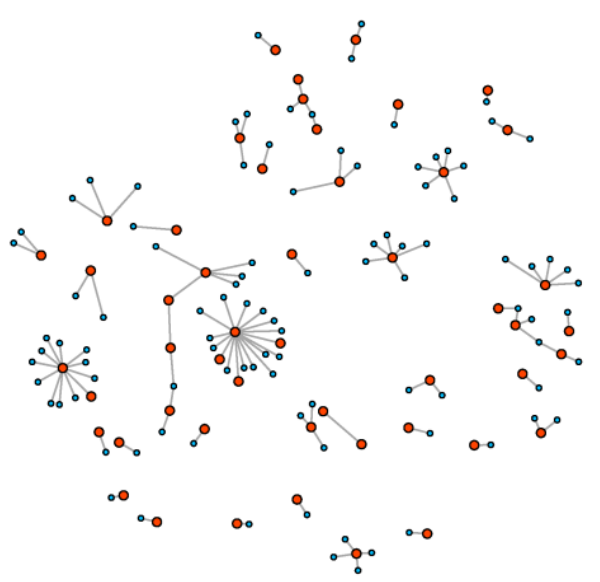

(a) Attended planning meetings

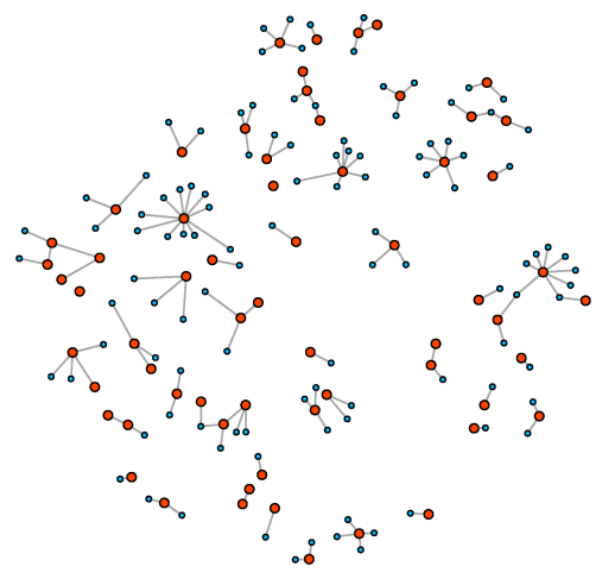

(c) Offered in-kind resources

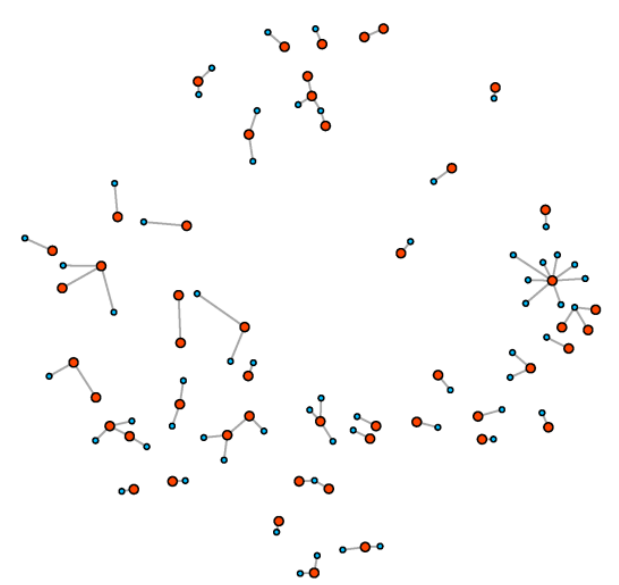

(e) Co-hosted the event

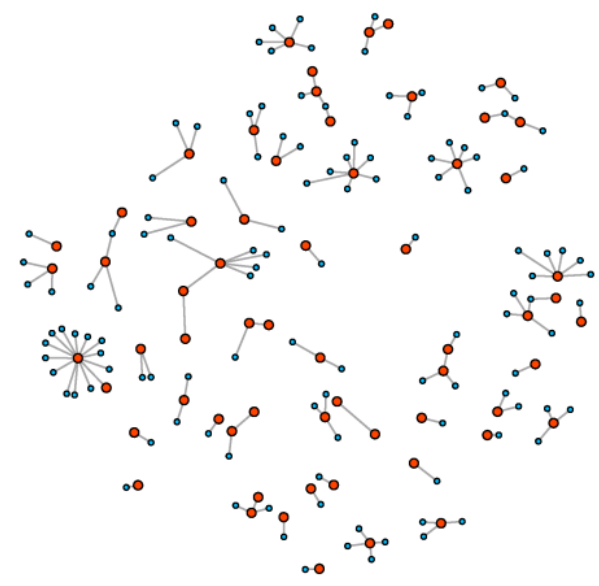

(b) Exchanged information/ideas

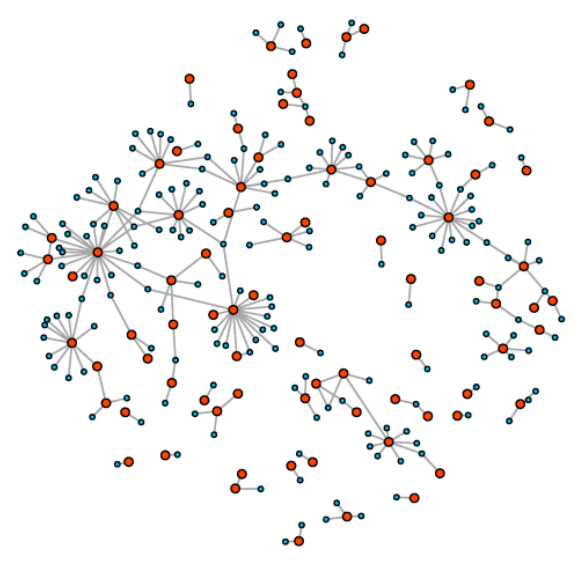

(d) Helped coordinate/lead events

Figure 3. Festival Partnerships based on Type of Assistance. 
Table 1. Frequency of the various types of assistance provided by type of organization.

\begin{tabular}{|c|c|c|c|c|c|c|c|}
\hline & $\begin{array}{l}\text { Attending } \\
\text { planning } \\
\text { meetings }\end{array}$ & $\begin{array}{l}\text { Exchanging } \\
\text { informa- } \\
\text { tion/ideas }\end{array}$ & $\begin{array}{l}\text { Offering } \\
\text { in-kind } \\
\text { resources }\end{array}$ & $\begin{array}{c}\text { Coordinate } \\
\text { and/or lead } \\
\text { event } \\
\text { activities }\end{array}$ & $\begin{array}{l}\text { Co-hosting } \\
\text { the event }\end{array}$ & $\begin{array}{l}\text { Providing } \\
\text { financial } \\
\text { sponsor- } \\
\text { ship }\end{array}$ & $\begin{array}{l}\text { Total } \\
\text { Org.* }\end{array}$ \\
\hline College/University & 23 & 20 & 16 & 34 & 11 & 6 & 37 \\
\hline Government Office/Dept & 26 & 29 & 31 & 46 & 6 & 7 & 50 \\
\hline Informal Learning Institution & 10 & 18 & 18 & 29 & 11 & 2 & 33 \\
\hline K-12 School/Education & 16 & 21 & 14 & 34 & 13 & 7 & 39 \\
\hline News/Media & 2 & 3 & 6 & 2 & 1 & 4 & 7 \\
\hline Non-Profit Organization & 20 & 31 & 23 & 56 & 20 & 9 & 58 \\
\hline Other & 4 & 4 & 3 & 5 & 1 & 2 & 5 \\
\hline Private Business/Industry & 19 & 29 & 30 & 36 & 6 & 9 & 52 \\
\hline Public/Private Green Space & 7 & 7 & 5 & 13 & 7 & 1 & 13 \\
\hline Public/Private Library & 0 & 1 & 0 & 4 & 2 & 0 & 4 \\
\hline Total & 127 & 163 & 146 & 259 & 78 & 47 & 296 \\
\hline
\end{tabular}

* Includes event hosts $(\mathrm{n}=29)$ who also partnered with other event hosts

back two years (2013) and almost half (47\%) went back three years (2012). Nearly one-quarter $(23 \%)$ of partnerships originated with the festival itself during its inaugural year (2010).

The connections between host organizations and partners extended beyond the festival as well. Of those organizations that have collaborated in previous festivals, $83 \%$ also work together on STEM learning activities beyond the festival context. As a result, the benefits of festival partnerships extend more broadly to promote STEM learning across the state. Particularly among festival-initiated partnerships, two out of every three led to additional STEM learning and activities beyond that first event.

\section{Case study examples}

Case study interviews were conducted to provide stories that demonstrate the kinds of partnerships created through the festival. Among the three case studies, each received varying types of support from their partners, e.g. serving as cohosts and/or providing financial support, which reflects varying levels of donations up to financial sponsorship.

Case study 1. Sylvan Heights Bird Park (SHBP) is a nonprofit organization located in Scotland Neck, North Carolina. SHBP began participating in the NCSF in 2012, hosting programs on their own and at the park. Celebrate Earth Day!, an expo-style program from the 2015 festival, was created and implemented with the help of 11 partners. Claudia Harrell, the park's volunteer coordinator for tours and outreach reflected, "When it came down to getting involved with the Science Festival [we] started going out and making these connections with these other organizations and having them all come to the Park... [it] has now given us a large network group that, perhaps without the festival, we would not have pushed ourselves to reach out to." 
Celebrate Earth Day! was created in collaboration with five existing partners who had been to the park to host events in the past, as well as six additional partners who were either entirely new to SHBP's network or who were visiting the park to cohost programming for the first time, thereby distributing the event's responsibilities and enabling SHBP to serve as the primary event host and contact with NCSF. This event serves as an example of how STEM educators have leveraged the festival to create and strengthen collaboration. Ali Lubbock, cofounder of SHBP said, "Celebrate Earth Day! was fantastic... It was one of the best days we have had for educating and entertaining, and it was a team effort with everyone combined." This program aligned the SHBP's mission to educate people about waterfowl and wetlands in the short term, while also building new partnerships that can help sustain SHBP's STEM programming for years to come.

Case study 2. The University of North Carolina-Charlotte (UNCC) began participating in the NCSF in 2012, and the university has added new festival programming every year since. Starting with an expo event in 2012, UNCC went on to add lectures to their festival calendar in 2013, and a film discussion series in 2014. The most recent addition to the UNCC calendar included events for children, featuring topics such as robotics and coding.

The festival has been a successful strategy for creating a stronger partnership between UNCC and the Charlotte Mecklenburg School District (CMS). Jim Hathaway organizes UNCC's festival events each year as part of his role as research communications specialist from the UNCC Research \& Economic Development Office. Hathaway, who cites the festival as a key proponent in UNCC's relationship with CMS said, "The festival becomes a way we kind of get together... We find out about schools that are interested in some of our programs through the things that we're doing, and they find out about faculty who are interested in coming in and doing programs and working with them... They really are a partner and value has come out of that."

Case study 3. Located in central North Carolina, C.W. Stanford Middle was the first and only middle school in the Orange County school district for many years. Recently, Stanford has taken steps to be named a STEM school and in 2015 the school produced STEM Career Expo to engage their community and to provide outreach to students related to STEM educational and career pursuits.

Erin Denniston and Jeff Faulkner, the district STEM coordinator and a science teacher at the school (respectively), led the charge. The idea was to bring professionals to the school from across the STEM disciplines to share the stories of their educational and career paths, and to lead the students in an activity related to their job. Like many festival programs, partners helped lead programming at the event. Denniston summarized, "So that way you got the beginning of the journey - this is how I got here, this is the classes I took in high school, this is what I'm doing in college, this is graduate [school], and then all right, this is what it looks like when you come out of that journey." In the end, the STEM Career Expo included 27 sessions and more than 40 STEM professionals. When asked to reflect on their success, Denniston said, "What I've come to realize, in talking with the few people that I talked with, they're chomping at the bit to get out here." Faulkner interjected, "And they didn't know how to interact with us." Denniston agreed, 
“They didn't know how... It's about a relationship. It's about talking to the kids. It's about making connections with the families in the community."

In a defining article published in 2006, Barron put forth a series of conjectures about learning ecosystems and the ways they might be investigated. Most relevant to this study is the idea that "a learning ecology is best conceptualized as a dynamic entity that can be characterized by the diversity and depth of learning resources and activities" (p. 217). Science festivals are good examples of such dynamic entities. This study is a first step in examining a science festival in relation to a STEM learning ecosystem.

The results from the social network analysis depict the interorganizational network of host organizations and partners that comprised the 2015 NCSF. The network reflected the simultaneous actions and interactions of multiple actors, where each action or interaction was that of an independently operating organization. In this case, the individual interactions of host organizations contributed to the formation of the complex festival network through the patterns of their interactions with their partners.

The findings also depicted the large and dynamic set of actors involved in the production of the NCSF. Indeed, the size and scope of the network exceeded expectations. Prior to this study, the emphasis on collaboration for the NCSF has been primarily between the lead festival producer, Morehead Planetarium and Science Center, and the organizations that agree to host events. Historically, information shared between NCSF organizers and host organizations had been limited to the logistical details of events and was not focused on the organizers themselves or their collaborators. The social network analysis revealed more than 170 organizations whose involvement with the festival was unknown to the organizers, further substantiating that the festival successfully seeds partnerships of STEM-minded organizations. The diversity of the host organizations, their collaborators, and the nature of their interactions also became clear, documenting the range of STEM actors involved in the festival. Importantly, many partnerships reflected key attributes of STEM learning ecosystems in that they occurred across sectors and included a range of collaborative activities [Traphagen and Traill, 2014].

Two ways that social network analysis describes network cohesion is by network density and network connectedness [Wasserman and Faust, 1994]. Reflected as the proportion of possible connections between organizations, the low density of the network reveals the festival's potential to stimulate STEM learning across the area. Opportunities exist to increase the number of partnerships by event hosts through increasing the average number of partners $(>2)$, as well as encouraging those event hosts who do not collaborate with others to partner with at least one (or more) organizations in the future. The NCSF outreach network is also characterized as having a relatively modest level of connectedness, suggesting there are gaps in the network that prevent some individual organizations from being truly connected to one another. This result is likely due to the distributed nature of the festival's design, which was not initiated with the goal of creating connections between all actors in the system. The gaps identified through this study highlight possible action areas where the NCSF team might broker connections to strengthen and build the network in the future. 
Though there is room for growth, the strength of the festival's network connections was made clear by several results. First, the analysis demonstrated that collaborations have increased over time, with the number of repeat collaborations increasing year after year. In addition, the majority of these organizations also partnered on STEM-related activities outside the context of the festival. From this it can be concluded that the NCSF is achieving a key goal of contributing to the growth of a STEM-rich ecosystem in the state.

Leadership roles in a STEM learning ecosystem can take two main forms: brokering and driving. Brokering is the intentional act of connecting organizations, communities, and learners [Bevan, 2016]. While the NCSF itself is not currently organized as a broker, it seems clear that host organizations have assumed this role as they lead festival programming. Both the case studies of University of North Carolina-Charlotte and C.W. Stanford Middle demonstrated brokerage behaviors; in both examples the leaders facilitated entrée of people from one sector to another by leveraging local resources for STEM education. In these cases, the NCSF served as a catalyst for these encounters, and thus considers this collaboration to be an outcome of the festival.

The findings highlight the potential for the NCSF to serve as an ecosystem driver by providing an organizational structure for collaboration across the learning ecosystem. Festivals often provide a platform for interaction that did not exist previously. The NCSF has created new opportunities for a diverse set of host organizations and partners to work with one another, while also providing new interactions between these groups and the public, the media and sponsors. The case studies included in this manuscript highlight the range of partnership opportunities created through the festival.

Science festivals are defined, in part, by the fact that they are time-limited and recurring celebrations [Bultitude, McDonald and Custead, 2011]. While the relatively short duration of a festival seems an insufficient amount of time to facilitate the cross-organizational learning and growth necessary to build capacity, the recurring nature of science festivals has the potential to facilitate their ability to be a driver. The increased number of recurring collaborations in the NCSF network over time indicates that organizations look to the festival each year precisely because it provides leadership and a platform to connect with others. The NCSF has become a constant in the state's STEM learning ecosystem. It seems likely that other festivals play a similar role in their local ecosystems as well. The Sylvan Heights Bird Park case study demonstrates the evolution of partnerships that might occur when actors come to rely on the recurring structure of a science festival.

Even so, the modest level of connectedness across the NCSF network suggests that there are gaps in the network that prevent actors from benefiting maximally from the knowledge and experience of the system as a whole. One factor that limits the extent to which the NCSF can play a driver role in the statewide STEM learning ecosystem is the network's low network centrality. The NCSF is organized by a small central organizing staff that relies on geographically dispersed partners to produce events in local communities across the state. As such, the network has a low degree of centralization by design. It would be unrealistic to expect a festival with this organizational structure to efficiently drive the learning ecosystem. Festivals with a high level of centralized coordination may have particular 
potential to serve as ecosystem drivers. As a next step, we propose a study to examine variation in the roles that festivals play in their local learning ecosystems based on their organizational structure.

While this study achieved excellent response rates, it does not reflect the entirety of the NCSF network. School-based events that were developed and distributed by festival staff were not included in this study, primarily because we wanted to focus on events where the format and implementation were not prescribed. Future investigations of the NCSF will include these school-based events to document the entire network.

Conclusions

This study affirms that collaboration is a key outcome of science festivals. A multitude of benefits from collaboration have been documented: expansion of the NCSF network, cross-sector interactions that provide people entrée to new communities and experiences, a variety of types of assistance taking place, and relationships to support STEM education that extend beyond the festival calendar. Encouraging collaborative activity through science festivals is wise; it is not a stretch to say that facilitating collaboration should become a key production strategy, and not just an outcome, of science festivals.

Science festivals clearly play the role of ecosystem catalysts in the communities they serve. The potential for science festivals to serve as brokers and/or drivers within STEM learning ecosystems seems great. Taking this step would involve intentionally identifying or creating common learning strategies and content across the ecosystem, and providing opportunities for organizations in the network to connect. Science festival organizers will have to decide if this is a role they want to assume, as it may require changes in organizational structure, management and activity.

References

Barron, B. (2006). 'Interest and Self-Sustained Learning as Catalysts of Development: A Learning Ecology Perspective'. Human Development 49 (4), pp. 193-224. DOI: 10.1159/000094368.

- (2014). Formative assessment for STEM learning ecosystems: Biographical approaches as a resource for research and practice. URL: http://sites . nationalacademies .or $\mathrm{g} / \mathrm{cs} /$ groups/dbassesite/documents/webpage/dbasse_089994.pdf.

Bevan, B. (2016). STEM Learning Ecologies. URL: http://csl.nsta.org/2016/03/stem-learning-ecologies/.

Bultitude, K., McDonald, D. and Custead, S. (2011). 'The Rise and Rise of Science Festivals: an international review of organised events to celebrate science'. International Journal of Science Education, Part B 1 (2), pp. 165-188. DOI: 10.1080/21548455.2011.588851.

Dillman, D. A., Smyth, J. D. and Christian, L. M. (2014). Internet, phone, mail, and mixed-mode surveys: The tailored design method. Hoboken, NJ, U.S.A.: Wiley \& Sons, Inc.

Fruchterman, T. M. J. and Reingold, E. M. (1991). 'Graph drawing by force-directed placement'. Software: Practice and Experience 21 (11), pp. 1129-1164. DOI: $10.1002 /$ spe. 4380211102 . 
Handcock, M. S., Hunter, D. R., Butts, C. T., Goodreau, S. M. and Morris, M. (2003). statnet: Software tools for the Statistical Modeling of Network Data. URL: http://statnetproject.org.

Manning, C. (2013). Results of the grad experiments. Panel presented at the Annual Meeting of the American Association for the Advancement of Science, Boston, MA, U.S.A. URL: https://aaas . confex.com/aaas/2013/webprogram/Paper9320.html.

Marsden, P. V. (2005). 'Recent Developments in Network Measurement'. In: Models and Methods in Social Network Analysis. Ed. by P. J. Carrington, J. Scott and S. Wasserman. New York, U.S.A.: Cambridge University Press, pp. 8-30.

National Research Council (2015). Identifying and Supporting Productive STEM Programs in Out-of-School Settings. Washington, D.C.: National Academies Press. URL: http: //www. nap. edu/catalog/21740.

Penuel, W. R. and Bevan, B. (2014). Designing and building infrastructures to support equitable STEM learning across settings. URL: http://learndbir.org/resources/Penuel-Lee-Bevan-2014.pdf.

Peterman, K. and Young, D. (2015). 'Mystery Shopping: An Innovative Method for Observing Interactions With Scientists During Public Science Events'. Visitor Studies 18 (1), pp. 83-102. DOI: 10.1080/10645578.2015.1016369.

Robertson, J. and Peterman, K. (September 2013). 2013 evaluation headlines. Report presented to the North Carolina Science Festival Advisory Board. Durham, NC, U.S.A.: Karen Peterman Consulting Co.

Science Festival Alliance (2015). Annual report of the Science Festival Alliance. URL: htt p://sciencefestivals .org/media/marketing/2014-SFA-Annual-Report . pdf.

Scott, J. (2000). Social Network Analysis: A Handbook. Thousand Oaks, CA, U.S.A.: SAGE Publications.

Traphagen, K. and Traill, S. (2014). How cross-sector collaborations are advancing STEM learning. Los Altos, CA, U.S.A.: Noyce Foundation.

Wasserman, S. and Faust, K. (1994). Social Network Analysis: Methods and Applications. Cambridge, U.K.: Cambridge University Press.

Wiehe, B. (2014). 'When science makes us who we are: known and speculative impacts of science festivals'. JCOM 13 (04), C02. URL: http://jcom. sissa.it/a rchive/13/04/JCOM_1304_2014_C01/JCOM_1304_2014_C02.

- (5th February 2016). Personal communication.

Christine A. Bevc, Ph.D., M.A., is a research public health analyst with RTI International, a nonprofit research institute. Her professional interests include the application of network science and social science research methods to better understand the patterns and partnerships among organizations; to improve inter-organizational relationships and collaboration; and identify factors that promote sustainable public health systems and services. http:/ / www.rti.org. E-mail: cbevc@rti.org.

Denise Young, Ed.D., is the director of education and planning at Morehead Planetarium and Science Center at the University of North Carolina at Chapel Hill. She is also the co-founder of the NC Science Festival. Her professional interests include promoting informal education as a vital part of the education landscape; defining the impact and value of public science events and centers for individuals 
and society; improving efforts of scientists to communicate their research (and its value) to the lay public; and creating new opportunities for university-based science centers to contribute to improved science education. www.moreheadplanetarium.org, www.ncsciencefestival.org E-mail: dlyoung@email.unc.edu.

Karen Peterman, Ph.D., is the President of Karen Peterman Consulting, Co., an evaluation and research company based on Durham, North Carolina. She is the external evaluator for the NC Science Festival. Her professional interests include the evaluation of STEM education projects, and a specific focus on effective evaluation methods that are appropriate for informal learning contexts. www.consultkp.com E-mail: karenpetermanphd@gmail.com.

Bevc, C. A., Young, D. and Peterman, K. (2016). 'Using social network analysis to document science festival partnerships'. JCOM 15 (05), A04. 